\title{
NMR studies of phosphorus chalcogenide-copper iodide coordination compounds
}

\author{
Gunther Brunklaus, ${ }^{a}$ Jerry C. C. Chan, ${ }^{a}$ Hellmut Eckert, ${ }^{* a}$ Sara Reiser, ${ }^{b}$ Tom Nilges ${ }^{b}$ \\ and Arno Pfitzner*b \\ ${ }^{a}$ Institut für Physikalische Chemie, Westfälische Wilhelms-Universität Münster, \\ Schlossplatz 7, D-48149 Münster, Germany \\ ${ }^{b}$ Institut für Anorganische Chemie, Universität Regensburg, D-93040 Regensburg, Germany
}

Received 31st March 2003, Accepted 1st July 2003

First published as an Advance Article on the web 30th July 2003

The local structures of the new phosphorus chalcogenide - copper iodide coordination compounds $(\mathrm{CuI}) \mathrm{P}_{4} \mathrm{Se}_{4},(\mathrm{CuI})_{2} \mathrm{P}_{8} \mathrm{Se}_{3},(\mathrm{CuI})_{3} \mathrm{P}_{4} \mathrm{Se}_{4}$, and $(\mathrm{CuI})_{3} \mathrm{P}_{4} \mathrm{~S}_{4}$ are investigated using comprehensive ${ }^{63} \mathrm{Cu},{ }^{65} \mathrm{Cu}$, and ${ }^{31} \mathrm{P}$ magic angle spinning NMR techniques. Peak assignments are proposed on the basis of homo- and heteronuclear indirect spin-spin interactions, available from lineshape analysis and/or two-dimensional correlation spectroscopy. In particular, the ${ }^{31} \mathrm{P}^{63,65} \mathrm{Cu}$ scalar coupling constants have been extracted from detailed lineshape simulations of the ${ }^{31} \mathrm{P}$ resonances associated with the $\mathrm{Cu}$-bonded $\mathrm{P}$ atoms. In addition, the $\mathrm{R} N_{n}^{\nu}$ pulse symmetry concept of Levitt and coworkers has been utilized for total through-bond correlation spectroscopy (TOBSY) of directly-bonded phosphorus species. The resonance assignments obtained facilitate a discussion of the ${ }^{31} \mathrm{P}$ and ${ }^{63,65} \mathrm{Cu}$ NMR Hamiltonian parameters in terms of the detailed local atomic environments. Analysis of the limited data set available for this group of closely related compounds offers the following conclusions: (1) bonding of a special phosphorus site in a given $\mathrm{P}_{4} \mathrm{X}_{\mathrm{n}}(\mathrm{X}=\mathrm{S}, \mathrm{Se})$ molecule to $\mathrm{Cu}^{+}$ ions shifts the corresponding ${ }^{31} \mathrm{P}$ NMR signal upfield by about $50 \mathrm{ppm}$ relative to the uncomplexed molecule, (2) the magnitude of the corresponding scalar ${ }^{31} \mathrm{P}-{ }^{63,65} \mathrm{Cu}$ spin-spin coupling constant tends to decrease with increasing $\mathrm{Cu}-\mathrm{P}$ distance, and $(3)$ the ${ }^{63,65} \mathrm{Cu}$ nuclear electric quadrupolar coupling constants appear to be weakly correlated with the shear strain parameter specifying the degree of local distortion present in the four-coordinated $\left[\mathrm{CuI}_{2} \mathrm{P}_{2}\right]$ and $\left[\mathrm{CuI}_{3} \mathrm{P}\right]$ environments. Overall, the results illustrate the power and potential of advanced solid state NMR methodology to provide useful structural information in this class of materials.

\section{Introduction}

The use of copper(I) halides as a preparative tool has recently been reported to be a successful strategy to compounds showing enhanced ionic conductivity. ${ }^{1,2}$ Along this route a new class of solid state materials has been generated in which phosphorus chalcogenide cages are being stabilized as copper iodide coordination compounds. This list includes the well known cage structures $\mathrm{P}_{4} \mathrm{~S}(\mathrm{e})_{3},{ }^{3-9}$ catena- $\mathrm{P}_{4} \mathrm{Se}_{4},{ }^{10}$ and $\beta$ $\mathrm{P}_{4} \mathrm{~S}_{4},{ }^{9,11}$ but also the hitherto unknown molecules $\mathrm{P}_{8} \mathrm{Se}_{3},{ }^{12}$ and $\beta-\mathrm{P}_{4} \mathrm{Se}_{4} \cdot{ }^{13}$ While all of the above materials have been structurally characterized by single-crystal X-ray diffraction, this method requires suitable crystals and cannot be applied to microcrystalline or even amorphous materials. Therefore, it is also of great interest to develop and utilize the potential of alternative experimental approaches with structural information content. In this regard, solid state nuclear magnetic resonance (NMR) spectroscopy provides an element-selective, inherently quantitative method that can offer very detailed insights into the local environments, bond connectivities, as well as structural or dynamic disorder of the building units involved. ${ }^{11,13}$ In the present contribution we will discuss the utility of one- and two-dimensional ${ }^{31} \mathrm{P}$ and ${ }^{63,65} \mathrm{Cu}$ NMR to characterize these features and reveal details on the interaction between the phosphorus chalcogenide cages and their more or less ionic environments. The crystallographically distinct phosphorus sites in these compounds are in general well-resolvable on the basis of their isotropic chemical shifts, obtained from the magic-angle spinning spectra. Since, unfortunately, the theoretical understanding of the chemical shifts measured in phosphorus chalcogenides is only poorly developed, the recovery and analysis of dipole-dipole and scalar interactions is of particular significance for peak assignments. Important information stems from the characteristic peak multiplet structures arising from heteronuclear indirect spin-spin interactions of the ${ }^{31} \mathrm{P}$ nuclei with the ${ }^{63,65} \mathrm{Cu}$ isotopes, which were first analyzed in detail in various $\mathrm{Cu}$-phosphine complexes. ${ }^{14,15} \mathrm{Com}-$ plementary insights into direct dipole-dipole interactions are accessible from ${ }^{31} \mathrm{P}\left\{{ }^{63} \mathrm{Cu}\right\}$ rotational echo adiabatic passage double resonance (REAPDOR) NMR studies. ${ }^{16}$ For probing homonuclear ${ }^{31} \mathrm{P}-{ }^{31} \mathrm{P}$ couplings a wide variety of dipolar recoupling techniques have been developed. ${ }^{17,18}$ For improved spectral selectivity, however, it is useful to focus on the analysis of indirect (scalar) spin-spin interactions, which can discriminate through-bond connectivity from mere spatial proximity. Thus, a variety of two-dimensional total-through-bond correlation spectroscopic (TOBSY) approaches have been described in the literature, ${ }^{19-27}$ enabling the selective correlation between those nuclei that are directly bonded. A particularly successful general concept for the development of suitable recoupling strategies has been the so-called $\mathrm{R} N_{n}^{\nu}$ pulse symmetry, introduced by Levitt and co-workers. ${ }^{28,29}$ Thanks to the flexibility and powerful features offered by this class of pulse sequences, some of the R $N_{n}^{\nu}$ pulse symmetries are well suited for TOBSYlike experiments. As previously shown in our laboratory, an extremely promising pulse symmetry for TOBSY-like experiments, which is rather insensitive to resonance offsets and experimental imperfections, is determined to be $\mathrm{R} 30_{6}^{14} \cdot{ }^{30}$ 
Simulations using the SIMPSON software package ${ }^{31}$ and validation experiments conducted on crystalline model compounds $^{32}$ have shown that R-TOBSY is fairly insensitive to the presence of through-space dipolar couplings, to the details of mutual spin tensor orientations, to large resonance offsets, and to experimental imperfections such as pulse power misadjustments and/or radio frequency inhomogeneities. ${ }^{30,32}$ These favourable properties are particularly advantageous for connectivity studies in phosphorus chalcogenide systems, which are quite generally characterized by wide spectral dispersions. It is the purpose of this study to explore the applicability of R-TOBSY as an assignment tool in the present class of coordination compounds, to extract their relevant NMR Hamiltonian parameters and to discuss their structural interpretation in conjunction with known crystallographic information. A preliminary account of results on $(\mathrm{CuI})_{3} \mathrm{P}_{4} \mathrm{~S}_{4}$ has been given previously ${ }^{11}$ and will be expanded upon in the present work.

\section{Experimental}

The following compounds were included in this study: $(\mathrm{CuI}) \mathrm{P}_{4} \mathrm{Se}_{4},(\mathrm{CuI})_{2} \mathrm{P}_{8} \mathrm{Se}_{3},(\mathrm{CuI})_{3} \mathrm{P}_{4} \mathrm{Se}_{4}$, and $(\mathrm{CuI})_{3} \mathrm{P}_{4} \mathrm{~S}_{4}$. These materials were prepared by standard high-temperature highvacuum techniques, following the previously published procedures. ${ }^{10-13}$ Compound purity was ascertained using standard $\mathrm{X}$-ray powder diffraction and magic-angle spinning NMR methods. Solid state ${ }^{63,65} \mathrm{Cu}$ and ${ }^{31} \mathrm{P}$ NMR spectra were obtained on Bruker DSX 400 and DSX 500 NMR spectrometers equipped with suitable magic-angle spinning (MAS) NMR probes. Samples were rotated in 2.5 or $4 \mathrm{~mm}$ zirconia rotors at spinning frequencies up to $30 \mathrm{kHz}$. Additional lowfield NMR spectra were recorded in a $4.7 \mathrm{~T}$ magnet. Typical $\pi / 2$-pulse lengths were set to $2-3 \mu \mathrm{s}$, except for ${ }^{63,65} \mathrm{Cu}$ spectra, which were measured with selective $\pi / 2$-pulses of $1 \mu$ s duration. If not stated otherwise, all spectra were recorded as rotor-synchronized spin echoes avoiding severe baseline distortions. Data analyses and lineshape simulations were carried out using the DMFIT ${ }^{33}$ and WSOLIDS1 ${ }^{34}$ simulation packages. Chemical shift references were solid $\mathrm{CuI}$ and $85 \% \mathrm{H}_{3} \mathrm{PO}_{4}$, respectively. Fig. 1 shows the R-TOBSY pulse sequence as used in the present study to probe direct ${ }^{31} \mathrm{P}-{ }^{31} \mathrm{P}$ bond connectivities. Following an excitation of single quantum coherence by a simple $\pi / 2$-pulse, the system evolves under the MAS Hamiltonian during the evolution period $t_{1}$, which is then terminated by the second $\pi / 2$-pulse. The mixing period comprises $k$ cycles of $\mathrm{R} N_{n}^{\nu}$ pulse symmetry causing coherence transfer between spins coupled by sufficiently strong indirect spin-spin interactions. Further details of the pulse sequence are described elsewhere. ${ }^{30}$ Two-dimensional R-TOBSY NMR experiments were carried out with the above spectrometer

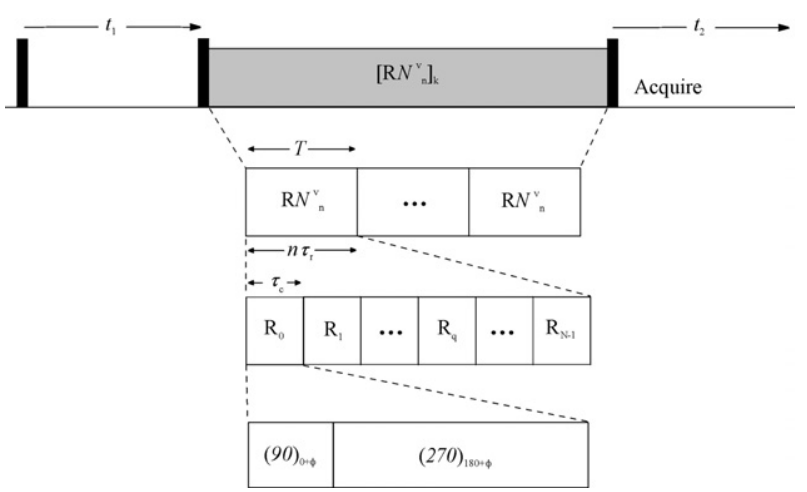

Fig. 1 The R $N_{n}^{\nu}$ pulse sequence in the context of TOBSY experiments. The three rectangular blocks in black represent $\pi / 2$ pulses. The mixing period sandwiched by the second and third $\pi / 2$ pulses comprise $k$ cycles of $\mathrm{R} N_{n}^{\nu}$ pulse symmetry. hardware at $4.7 \mathrm{~T}, 9.4 \mathrm{~T}$, and $11.7 \mathrm{~T}$, using an rf nutation frequency of five times the MAS rotation frequency. In one case, an additional three-step supercycle for enhanced zeroquantum filtering was included applying $2 \pi / 3$ phase shifts to each basic $\mathrm{R} 30_{6}^{14}$ block. $^{35}$ Detailed experimental conditions are given in the corresponding figure captions. Mixing times were optimized on the basis of one- or two-dimensional coherence transfer experiments. Quadrature detection in the F1dimension was achieved by the hypercomplex approach (STATES method). ${ }^{36}$ Saturation combs were applied before the relaxation delays for all experiments.

\section{Results}

\section{1. $(\mathrm{CuI}) \mathrm{P}_{4} \mathrm{Se}_{4}$}

The structure of this compound is characterized by neutral polymeric $\mathrm{P}_{4} \mathrm{Se}_{4}$ strands which are linked by copper atoms thereby forming layers parallel to (010) ( $c f$. Fig. 2a). The strands themselves consist of norbornane-type $\mathrm{P}_{4} \mathrm{Se}_{3}$ cages comprised of $\mathrm{P}_{2}$-dumbbells connected by selenium atoms. In addition, the cages are bridged by exocyclic selenium atoms revealing $\mathrm{P}_{4} \mathrm{Se}_{4}$ polymers, which are attached to copper atoms exclusively by the bridgehead phosphorus atoms as is illustrated in Fig. 2b. The distorted tetrahedral environment of the copper atoms is completed by iodine atoms. Fig. 3 shows the ${ }^{63} \mathrm{Cu}$ solid state MAS NMR spectrum, reflecting strong second-order quadrupolar perturbations arising from the local electric field gradients (EFG) present at the copper site. Table 1 summarizes the ${ }^{63} \mathrm{Cu}$ NMR lineshape parameters obtained by the DMFIT routine for all of the compounds investigated here. ${ }^{65} \mathrm{Cu}$ NMR data recorded for comparison were found to be consistent with the intrinsic difference of the quadrupolar moments of both $\mathrm{Cu}$ isotopes $\left(e Q\left({ }^{63} \mathrm{Cu}\right)=1.6 \times 10^{-33} \mathrm{~m}^{2}\right.$, $\left.e Q\left({ }^{65} \mathrm{Cu}\right)=1.5 \times 10^{-33} \mathrm{~m}^{2}, \Delta e Q \approx 6.7 \%\right)$. The ${ }^{77} \mathrm{Se}$ MAS spectrum (data not shown) of $(\mathrm{CuI}) \mathrm{P}_{4} \mathrm{Se}_{4}$ reveals three peaks at $\delta=-588 \mathrm{ppm}, \delta=-790 \mathrm{ppm}$ and $\delta=-858 \mathrm{ppm}$. Within the experimental errors, the integrated area ratio was found to be $1: 2: 1$, which clearly confirms the three crystallographically
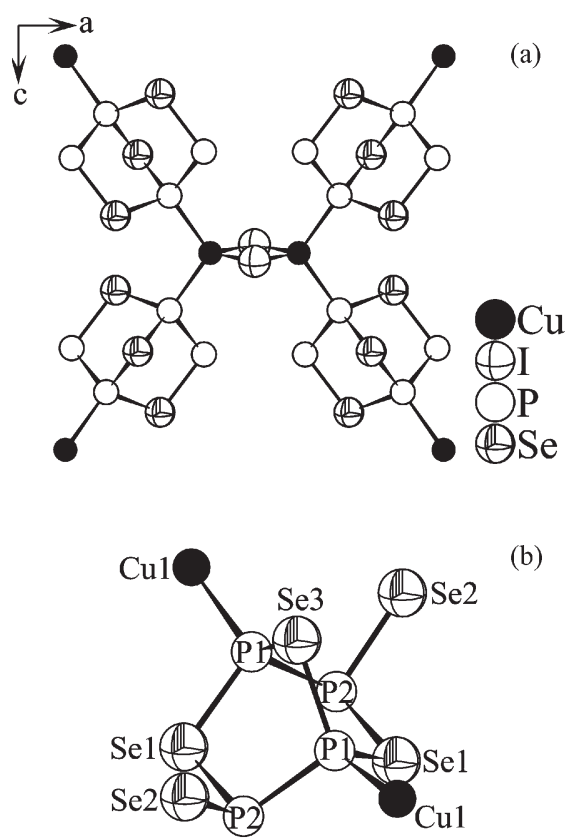

(b)

Fig. 2 (a) Crystal structure of $(\mathrm{CuI}) \mathrm{P}_{4} \mathrm{Se}_{4}$ shown as a projection along the $b$ axis. $\mathrm{P}_{4} \mathrm{Se}_{4}$ strands are linked by copper atoms producing layers parallel to $(010)$. (b) The basic building block: a norbornanetype $\mathrm{P}_{4} \mathrm{Se}_{3}$ cage bridged by selenium atoms. Exclusively the bridgehead phosphorus atoms are bonded to copper. 


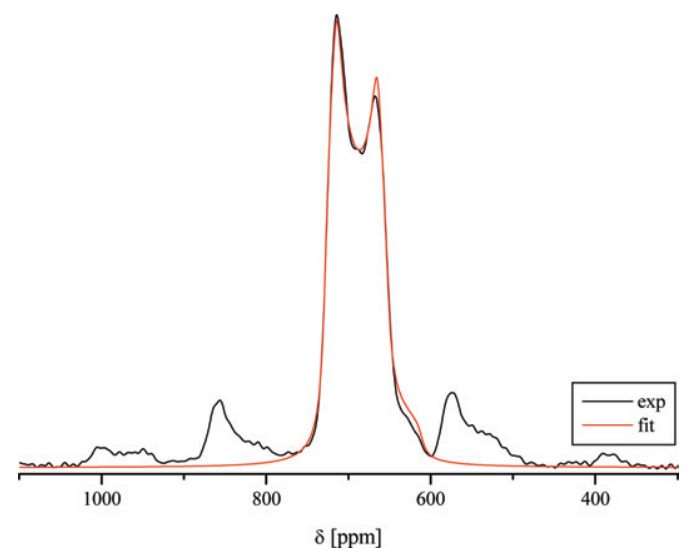

Fig. $3{ }^{63} \mathrm{Cu}$ MAS spectrum of $(\mathrm{CuI}) \mathrm{P}_{4} \mathrm{Se}_{4}$ at $9.4 \mathrm{~T}(106.08 \mathrm{MHz})$ and a spinning frequency of $15 \mathrm{kHz}$. The minor peaks are spinning side bands.

distinct selenium sites. Hence, the resonance at $\delta=-790 \mathrm{ppm}$ can be assigned to the selenium site Se1 whereas further peak assignments remain impossible at this stage.

The ${ }^{31} \mathrm{P}$ MAS-NMR spectrum ( $c f$. Fig. 4) consists of two main resonances centered at $\delta_{(\mathrm{P} 1)}=78.7 \mathrm{ppm}$ and $\delta_{(\mathrm{P} 2)}=$ $137.0 \mathrm{ppm}$, respectively, with an integrated area ratio of $\approx 1: 1$. The peak assigned to the crystallographic phosphorus site P1 is split into a multiplet due to the residual dipolar and scalar couplings to the quadrupolar ${ }^{63} \mathrm{Cu}$ and ${ }^{65} \mathrm{Cu}$ nuclei associated with the directly bonded $\mathrm{Cu} 1$ site. Using WSOLIDS1, the lineshape for the multiplet is simulated as a sum of two components reflecting the ${ }^{63} \mathrm{Cu} /{ }^{65} \mathrm{Cu}$ isotopic abundance ratio of $69.1 \% / 30.9 \% \approx 2.236$. Furthermore, in agreement with typical literature data, ${ }^{15}$ the anisotropy $\Delta J$ of the indirect dipole-dipole interaction tensor was held fixed at $500 \mathrm{~Hz}$ for all of the compounds studied. With the particular

Table $1{ }^{63} \mathrm{Cu}$ and/or ${ }^{65} \mathrm{Cu}$ NMR isotropic chemical shifts $\delta_{\text {iso }}( \pm 2$ $\mathrm{ppm})$, nuclear electric quadrupolar coupling constant $C_{\mathrm{Q}}( \pm 0.2$ $\mathrm{MHz})$ and electric field gradient asymmetry parameter $\eta( \pm 0.1)$ obtained on the phosphorus chalcogenide-copper iodide coordination compounds. All the data are from MAS, and for $(\mathrm{CuI})_{2} \mathrm{P}_{8} \mathrm{Se}_{3}$ additional data obtained from the static spectra are included in parentheses. Also listed is the shear strain parameter $\chi$ (defined in the text) computed from the crystal structure

\begin{tabular}{|c|c|c|c|c|c|c|}
\hline Site & \multicolumn{2}{|c|}{$\delta_{\text {iso }} / \mathrm{ppm}$} & \multicolumn{2}{|c|}{$C_{\mathrm{Q}}[\mathrm{MHz}]$} & $\eta$ & $\chi$ \\
\hline \multicolumn{7}{|c|}{$(\mathrm{CuI}) \mathrm{P}_{4} \mathrm{Se}_{4}$} \\
\hline${ }^{63} \mathrm{Cu} 1$ & 740 & \multicolumn{3}{|c|}{4.8} & 0.18 & 0.52 \\
\hline${ }^{65} \mathrm{Cu} 1$ & 735 & \multicolumn{3}{|c|}{4.6} & 0.14 & 0.52 \\
\hline Site & $\delta_{\text {iso }} / \mathrm{ppm}$ & $C_{\mathrm{Q}} / \mathrm{MHz}$ & $\eta$ & & $\chi$ & $\%$ \\
\hline \multicolumn{7}{|c|}{$(\mathrm{CuI})_{2} \mathrm{P}_{8} \mathrm{Se}_{3}$} \\
\hline $\mathrm{Cu} 1$ & $815(790)$ & $10.7(9.3)$ & & $(0.10)$ & 0.63 & $58(45)$ \\
\hline $\mathrm{Cu} 2$ & $626(751)$ & $6.3(7.2)$ & & $(0.27)$ & 0.41 & $42(55)$ \\
\hline Site & $\delta_{\text {iso }} / \mathrm{ppm}$ & $C_{\mathrm{Q}} / \mathrm{M}$ & & $\eta$ & $\chi$ & $\%$ \\
\hline \multicolumn{7}{|c|}{$(\mathrm{CuI})_{3} \mathrm{P}_{4} \mathrm{Se}_{4}$} \\
\hline $\mathrm{Cul}$ & 408 & 4.3 & & 0.39 & 0.30 & 28 \\
\hline $\mathrm{Cu} 2$ & 300 & 5.9 & & 0.20 & 0.47 & 37 \\
\hline $\mathrm{Cu} 3$ & 305 & 6.6 & & 0.13 & 0.50 & 35 \\
\hline Site & $\delta_{\text {iso }} / \mathrm{ppm}$ & $C_{\mathrm{Q}} / \mathrm{\perp}$ & & $\eta$ & $\chi$ & $\%$ \\
\hline \multicolumn{7}{|c|}{$(\mathrm{CuI})_{3} \mathrm{P}_{4} \mathrm{~S}_{4}$} \\
\hline${ }^{63} \mathrm{Cu} 1$ & 419 & 2.84 & & 0.50 & 0.29 & 31 \\
\hline${ }^{63} \mathrm{Cu} 2$ & 331 & 7.04 & & 0.03 & 0.43 & 69 \\
\hline${ }^{65} \mathrm{Cu} 1$ & 415 & 2.75 & & 0.55 & 0.29 & 33 \\
\hline${ }^{65} \mathrm{Cu} 2$ & 337 & 6.89 & & 0.17 & 0.43 & 67 \\
\hline
\end{tabular}

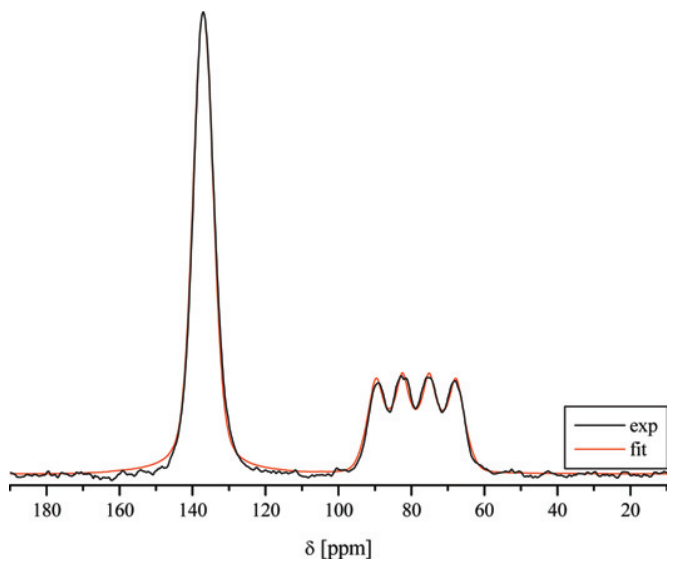

Fig. $4{ }^{31} \mathrm{P}$ MAS spectrum of $(\mathrm{CuI}) \mathrm{P}_{4} \mathrm{Se}_{4}$ at $7.1 \mathrm{~T}(121.49 \mathrm{MHz})$ and a spinning frequency of $30 \mathrm{kHz}$.

set of interaction parameters relevant here, variations of $\Delta J$ by $100 \%$ had no significant effect on the simulated lineshapes. The values for the dipolar coupling constants given in Table 2 are readily computed from the crystal structure, whereas the isotropic $J$ values were obtained via lineshape fitting, using the quadrupolar coupling parameters determined independently from the $\mathrm{Cu}$ NMR spectra and the additional constraint that ${ }^{1} J\left({ }^{63} \mathrm{Cu}-{ }^{31} \mathrm{P}\right) /{ }^{1} J\left({ }^{65} \mathrm{Cu}-{ }^{31} \mathrm{P}\right)=\gamma\left({ }^{63} \mathrm{Cu}\right) / \gamma\left({ }^{65} \mathrm{Cu}\right)$. Since there is no independent knowledge concerning the mutual orientations of the $\mathrm{Cu}$-electric field gradient axes with respect to the $\mathrm{Cu}-\mathrm{P}$ interaction tensor, the corresponding Euler angles $\alpha, \beta$ and $\gamma$ were systematically varied. The multiplet intensity

Table $2{ }^{31} \mathrm{P}$ NMR Hamiltonian parameters $\delta_{\text {iso }}( \pm 1 \mathrm{ppm})$ and ${ }^{1} J_{\text {iso }}\left({ }^{31} \mathrm{P}_{-}{ }^{63,65} \mathrm{Cu}\right)( \pm 10 \mathrm{~Hz})$ obtained on the phosphorus chalcogenidecopper iodide coordination compounds. Dipolar coupling constants $D$ are calculated from known internuclear distances.

\begin{tabular}{|c|c|c|c|c|}
\hline Sites/spin pairs & $\delta_{\text {iso }} / \mathrm{ppm}$ & $D / \mathrm{Hz}$ & $J_{\text {iso }} / \mathrm{Hz}$ & $\%$ \\
\hline \multicolumn{5}{|l|}{$(\mathrm{CuI}) \mathrm{P}_{4} \mathrm{Se}_{4}$} \\
\hline $\mathrm{P} 1-{ }^{63} \mathrm{Cu}$ & 78.7 & 1090 & 867 & 34.6 \\
\hline $\mathrm{P} 1-{ }^{65} \mathrm{Cu}$ & 78.7 & 1167 & 928 & 15.4 \\
\hline $\mathrm{P} 2$ & 137.0 & - & - & 50 \\
\hline Sites & \multicolumn{2}{|c|}{$\delta_{\text {iso }} / \mathrm{ppm}$} & & $\%$ \\
\hline \multicolumn{5}{|l|}{$(\mathrm{CuI})_{2} \mathrm{P}_{8} \mathrm{Se}_{3}$} \\
\hline $\mathrm{P} 1\left(\mathrm{P} 1^{\prime}\right)$ & \multicolumn{2}{|c|}{-44} & & 23 \\
\hline $\mathrm{P} 2\left(\mathrm{P} 2^{\prime}\right)$ & \multicolumn{2}{|c|}{94} & & 24 \\
\hline $\mathrm{P} 3\left(\mathrm{P} 3^{\prime}\right)$ & \multicolumn{2}{|c|}{83.6} & & 27 \\
\hline $\mathrm{P} 4\left(\mathrm{P}^{\prime}\right)$ & \multicolumn{2}{|c|}{105.2} & & 26 \\
\hline Sites/spin pairs & $\delta_{\text {iso }} / \mathrm{ppm}$ & $D / \mathrm{Hz}$ & $J_{\text {iso }} / \mathrm{Hz}$ & $\%$ \\
\hline \multicolumn{5}{|l|}{$(\mathrm{CuI})_{3} \mathrm{P}_{4} \mathrm{Se}_{4}$} \\
\hline $\mathrm{P} 1-{ }^{63} \mathrm{Cu} 1$ & 120.2 & 1143 & 1210 & 17.5 \\
\hline $\mathrm{P} 1-{ }^{65} \mathrm{Cu} 1$ & 120.2 & 1224 & 1297 & 7.5 \\
\hline $\mathrm{P} 4-{ }^{63} \mathrm{Cu} 2$ & 135.9 & 1132 & 1200 & 19.2 \\
\hline $\mathrm{P} 4-{ }^{65} \mathrm{Cu} 2$ & 136.1 & 1212 & 1286 & 8.3 \\
\hline $\mathrm{P} 2-{ }^{63} \mathrm{Cu} 3$ & 133.0 & 1112 & 1100 & 15.7 \\
\hline $\mathrm{P} 2-{ }^{65} \mathrm{Cu} 3$ & 133.0 & 1190 & 1178 & 6.8 \\
\hline $\mathrm{P} 3$ & 78.4 & - & - & 25 \\
\hline Sites/spin pairs & $\delta_{\text {iso }} / \mathrm{ppm}$ & $D / \mathrm{Hz}$ & $J_{\text {iso }} / \mathrm{Hz}$ & $\%$ \\
\hline \multicolumn{5}{|l|}{$(\mathrm{CuI})_{3} \mathrm{P}_{4} \mathrm{~S}_{4}$} \\
\hline $\mathrm{P} 1-{ }^{63} \mathrm{Cu} 1$ & 144.9 & 1176 & 1200 & 17.1 \\
\hline $\mathrm{P} 1-{ }^{65} \mathrm{Cu} 1$ & 144.9 & 1258 & 1284 & 7.7 \\
\hline $\mathrm{P} 2-{ }^{63} \mathrm{Cu} 2$ & 117.3 & 1154 & 1200 & 34.2 \\
\hline $\mathrm{P} 2-{ }^{65} \mathrm{Cu} 2$ & 117.3 & 1235 & 1284 & 15.3 \\
\hline P3 & 83.0 & - & - & 25.7 \\
\hline
\end{tabular}


distributions were found to be only marginally affected by these parameters and consequently, we assumed $\alpha=\beta=$ $\gamma=45^{\circ}$ in all simulations to represent the most general case. The final simulation results for all four compounds are summarized in Table 2. Fig. 5 demonstrates the P1-P2 connectivity in $(\mathrm{CuI}) \mathrm{P}_{4} \mathrm{Se}_{4}$ using the two-dimensional R-TOBSY experiment. Successful coherence transfer via the scalar coupling is illustrated by the crosspeaks linking the two resonances. The spectrum confirms that the presence of the dominant ${ }^{31} \mathrm{P}-{ }^{63,65} \mathrm{Cu}$ heteronuclear scalar interactions does not interfere with the applicability of R-TOBSY of achieving homonuclear coherence transfer between the directly bonded ${ }^{31} \mathrm{P}$ spins.

\section{2. $(\mathrm{CuI})_{2} \mathrm{P}_{8} \mathrm{Se}_{3}$}

The crystal structure of this compound consists of planar $\mathrm{Cu}_{2} \mathrm{I}_{2}$ rhomboids and novel $\mathrm{P}_{8} \mathrm{Se}_{3}$ cages arranged in layers parallel to (001) as depicted in Fig. $6 .{ }^{12}$ The $\mathrm{P}_{8} \mathrm{Se}_{3}$ cage can in principle be derived from a $\mathrm{P}_{8}$ cube by inserting selenium atoms into the three edges related by a threefold axis of the cube. Due to the crystallographic packing effects, however, the intrinsic $D_{3}$ symmetry of the $\mathrm{P}_{8} \mathrm{Se}_{3}$ cage molecule is reduced to $C_{2}$ symmetry. Since both the copper and iodine atoms are crystallographically inequivalent, a slight deviation from an ideal rhomboid is present while the coordination of four phosphorus atoms of the $\mathrm{P}_{8} \mathrm{Se}_{3}$ cage to two copper atoms with a $\mathrm{P}-\mathrm{Cu}$ distance of about $228 \mathrm{pm}$ is a similar motif as previously found for $(\mathrm{CuI}) \mathrm{P}_{4} \mathrm{Se}_{4}$.

The static ${ }^{63} \mathrm{Cu}$ spinecho-NMR spectrum shown in Fig. 7 reflects strong second-order quadrupolar perturbations owing to the local electric field gradients (EFGs) present at both copper sites. Their isotropic chemical shifts are quite similar producing strong overlap even at high magnetic field strengths. Nevertheless, the lineshape analysis of the ${ }^{63} \mathrm{Cu}$ spectrum of $(\mathrm{CuI})_{2} \mathrm{P}_{8} \mathrm{Se}_{3}$ clearly uncovers the inequivalence of both copper sites with an integrated area ratio of about 1:1 revealing strongly different quadrupolar coupling constants: Resonance A is characterized by $\delta_{\mathrm{CS}}=790 \mathrm{ppm}, C_{\mathrm{Q}}=9.3 \mathrm{MHz}$ and $\eta=0.10$, whereas signal $\mathrm{B}$ is characterized by $\delta_{\mathrm{CS}}=751$ ppm, $C_{\mathrm{Q}}=7.2 \mathrm{MHz}$ and $\eta=0.27$. Tentatively, we assign resonance $\mathrm{A}$ to the more distorted $\mathrm{Cu}$ site $\mathrm{Cu} 1$, and resonance

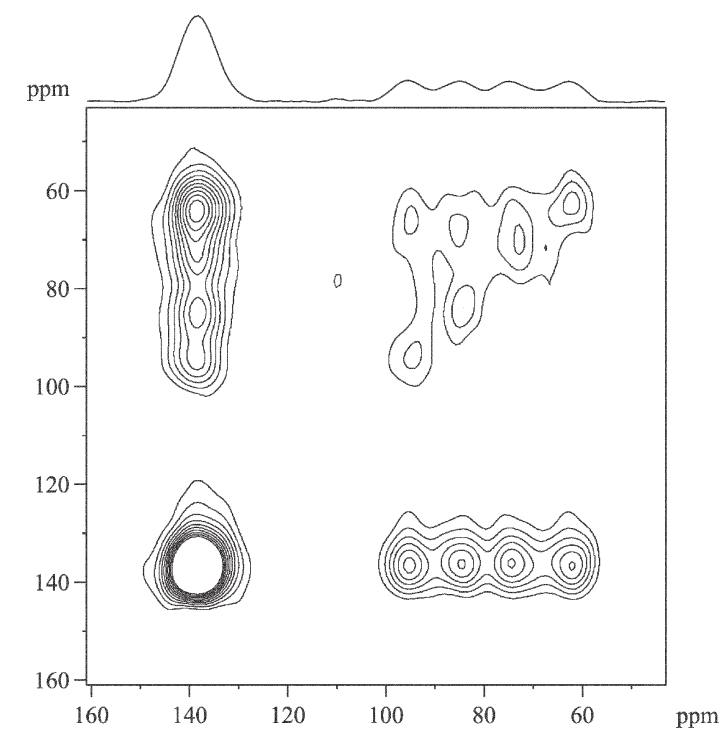

Fig. $5{ }^{31} \mathrm{P}-12 \mathrm{kHz}$ MAS SC-R-TOBSY spectrum of $(\mathrm{CuI}) \mathrm{P}_{4} \mathrm{Se}_{4}$ at $4.7 \mathrm{~T}(81.02 \mathrm{MHz})$ under the following experimental conditions: $\tau_{\text {mix }}=12.0 \mathrm{~ms}, 40 t_{1}$ increments at steps of $83.33 \mu \mathrm{s}$, relaxation delay $30 \mathrm{~s}$. Quadrature detection in the $F_{1}$ dimension was achieved by the hypercomplex approach (STATES). Ten positive contour levels between $5 \%$ and $40 \%$ of the maximum peak intensity are plotted. The $F_{2}$ projection is shown on the top.

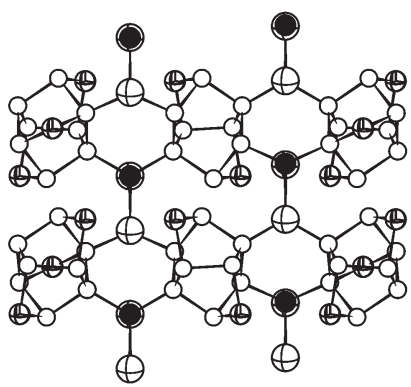

(a)

(b)
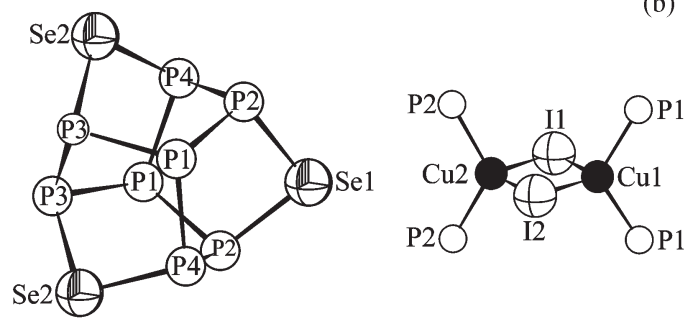

Fig. 6 (a) A projection along the $a$-axis of the crystal structure of $(\mathrm{CuI})_{2} \mathrm{P}_{8} \mathrm{Se}_{3}$. The $\mathrm{P}_{8} \mathrm{Se}_{3}$ cages and the $\mathrm{Cu}_{2} \mathrm{I}_{2}$ rhomboids are arranged in layers parallel to (001). Only half of the phosphorus atoms are attached to copper. (b) The basic units: the novel $\mathrm{P}_{8} \mathrm{Se}_{3}$ cage and the $\mathrm{Cu}_{2} \mathrm{I}_{2}$ rhomboid.

B to $\mathrm{Cu} 2$. Fig. 7b shows the corresponding MAS-NMR spectrum along with the peak deconvolution. While the quadrupolar coupling constants obtained are roughly consistent with those measured from the static spectrum, we note a significant

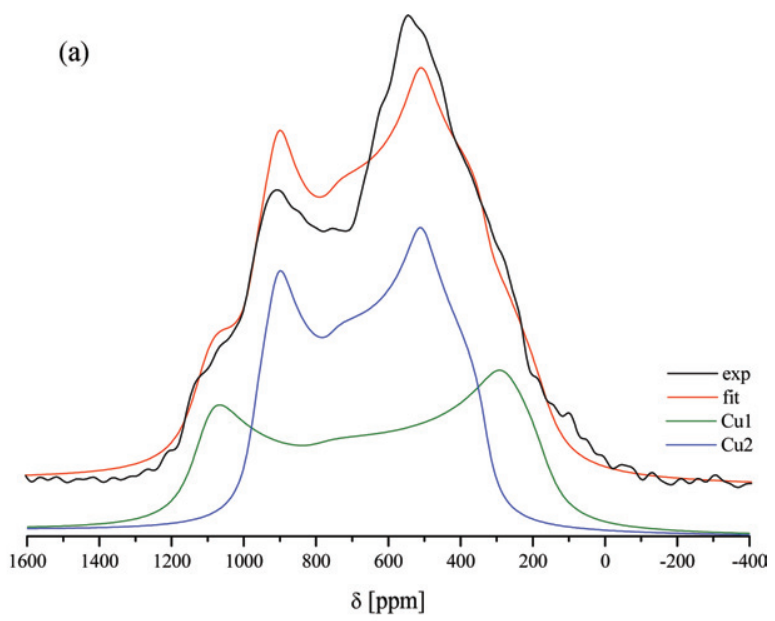

(b)

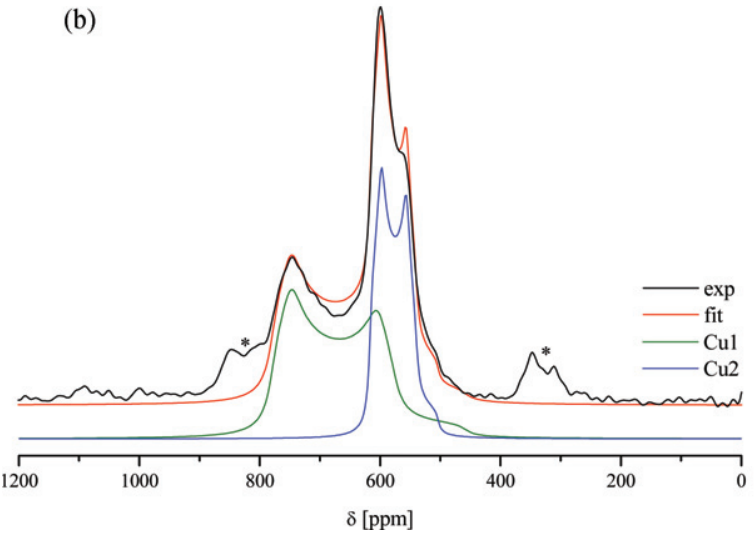

Fig. $7{ }^{65}$ (a) $\mathrm{Cu}$ static spinecho spectrum of $(\mathrm{CuI})_{2} \mathrm{P}_{8} \mathrm{Se}_{3}$ at $9.4 \mathrm{~T}$ $(113.70 \mathrm{MHz})$. The evolution time was set to $20 \mu \mathrm{s}$. Below the individual lineshapes of the two copper sites present are given. (b) $35 \mathrm{kHz}$ ${ }^{65} \mathrm{Cu}-\mathrm{MAS}$ NMR spectrum of $(\mathrm{CuI})_{2} \mathrm{P}_{8} \mathrm{Se}_{3}$ at $11.7 \mathrm{~T}(142.01 \mathrm{MHz})$. The contributions of both copper sites are given. Spinning sidebands are marked with asteriks. 
discrepancy for the isotropic chemical shift value of the $\mathrm{Cu} 2$ site between both measurements. This experimental uncertainty, documented in Table 1, might arise from the fact that the static spectrum is also affected by chemical shift anisotropy effects distorting the second-order quadrupolar lineshape.

The four distinct phosphorus atoms give rise to separate peaks in the ${ }^{31} \mathrm{P}$ MAS-NMR spectrum of $(\mathrm{CuI})_{2} \mathrm{P}_{8} \mathrm{Se}_{3}$, which are, however, not completely resolved from each other (data not shown). Furthermore, unlike the situation in $(\mathrm{CuI}) \mathrm{P}_{4} \mathrm{Se}_{4}$, the peak splittings arising from ${ }^{31} \mathrm{P}_{-}{ }^{63,65} \mathrm{Cu}$ scalar coupling are not clearly evident. This result may either reflect weaker ${ }^{31} \mathrm{P}_{-}{ }^{63,65} \mathrm{Cu}$ scalar interactions than in $(\mathrm{CuI}) \mathrm{P}_{4} \mathrm{Se}_{4}$ or more rapid spin fluctuations limiting the lifetimes of the ${ }^{63,65} \mathrm{Cu} \mathrm{Zee}-$ man states. Still, it appears likely that the significant broadening of the ${ }^{31} \mathrm{P}$ resonance at $\delta=-44.0 \mathrm{ppm}$ arises from unresolved scalar couplings, suggesting an assignment to one of the copper coordinated phosphorus sites $\mathrm{P} 1\left(\mathrm{P}^{\prime}\right)$ or $\mathrm{P} 2\left(\mathrm{P} 2^{\prime}\right)$. This suggestion can be independently checked by probing the ${ }^{63} \mathrm{Cu}-{ }^{31} \mathrm{P}$ heteronuclear dipole-dipole interactions. Successful dipolar recoupling to quadrupolar nuclei is accomplished by the REAPDOR sequence ${ }^{16}$ predicting a noticeable drop of signal intensity of those ${ }^{31} \mathrm{P}$ resonances associated with the sites $\mathrm{P} 1\left(\mathrm{P}^{\prime}\right)$ and $\mathrm{P} 2\left(\mathrm{P} 2^{\prime}\right)$, when the copper spins are irradiated during the rotor cycle. Generally, both copper isotopes are suitable, but owing to the larger natural abundance of the ${ }^{63} \mathrm{Cu}$ isotope, the ${ }^{31} \mathrm{P}\left\{{ }^{63} \mathrm{Cu}\right\}-\mathrm{REAPDOR}$ experiment is preferred. Fig. 8 presents a typical result. The extent of signal attenuation depends on both the magnitude of the quadrupolar coupling constant and on the ability of the recoupling pulse on the ${ }^{63} \mathrm{Cu}$ channel to change the ${ }^{63} \mathrm{Cu}$ spin states adiabatically, which in turn depends on the nutation frequency $\omega_{1}$. Using a dipolar evolution time of -0.94 $\mathrm{ms}\left(14 \tau_{\mathrm{r}}\right)$ and a recoupling pulse length of $33 \mu \mathrm{s}\left(\approx \tau_{\mathrm{r}} / 2\right)$ at $\omega_{1}=83.3 \mathrm{kHz}$ signal losses of $16 \pm 1 \%$ and $10 \pm 1 \%$ were obtained for the resonances centered near -44 and $94 \mathrm{ppm}$, respectively, whereas they were found only near 3-4 $\pm 1 \%$ for the other signals. We thus conclude that the signals at -44 and $94 \mathrm{ppm}$ correspond to the directly $\mathrm{Cu}$-coordinated $\mathrm{P} 1\left(\mathrm{P}^{\prime}\right)$ and $\mathrm{P} 2\left(\mathrm{P}^{\prime}\right)$ sites. The difference between $10 \pm 1 \%$ and $16 \pm 1 \%$ probably reflects the fact that the large $C_{\mathrm{Q}}$ difference between the two $\mathrm{Cu}$ sites $(\approx 30 \%)$ makes it impossible to adjust optimum REAPDOR conditions for both ${ }^{31} \mathrm{P}_{-}{ }^{63} \mathrm{Cu}$ spin

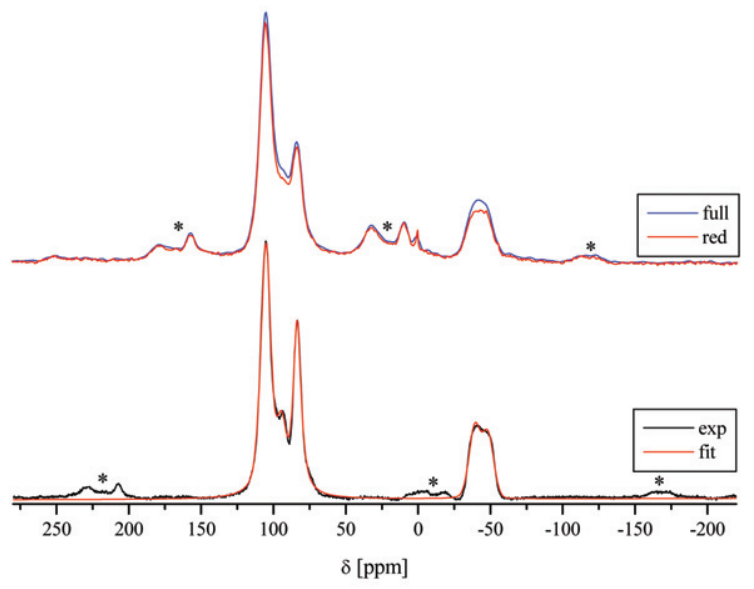

Fig. $8{ }^{31} \mathrm{P}-\left\{{ }^{63} \mathrm{Cu}\right\}$-REAPDOR of $(\mathrm{CuI})_{2} \mathrm{P}_{8} \mathrm{Se}_{3}$ at $11.7 \mathrm{~T}(202.45$ $\mathrm{MHz}$ ) and a spinning frequency of $15 \mathrm{kHz}$ with a recoupling pulse of $33 \mu \mathrm{s}(\approx$ half the rotor period $)$ applied on the ${ }^{63} \mathrm{Cu}$ channel. The dipolar evolution time was set to $0.94 \mathrm{~ms}\left(\approx 14 \tau_{r}\right)$ with $\omega_{1}\left({ }^{63} \mathrm{Cu}\right)=83.3 \mathrm{kHz}$ [blue: full spectrum without ${ }^{63} \mathrm{Cu}$ irradiation; red: reduced spectrum with ${ }^{63} \mathrm{Cu}$ irradiation.] The sharp peak next to $0 \mathrm{ppm}$ indicates partial hydrolysis of the sample. At the bottom, the $25 \mathrm{kHz}{ }^{31}$ P-MAS NMR spectrum at $11.7 \mathrm{~T}(202.45 \mathrm{MHz})$ is also shown. Spinning sidebands are marked with asterisks. pairs simultaneously. A complementary approach to uncover the connectivities of the $\mathrm{P}_{8} \mathrm{Se}_{3}$ cage molecule is achieved employing the R-TOBSY sequence. In the case of $(\mathrm{CuI})_{2} \mathrm{P}_{8} \mathrm{Se}_{3}$, the optimum mixing time was adjusted to $2 \mathrm{~ms}$ according to a one-dimensional parameter optimization procedure. The resulting 2D-spectrum is presented in Fig. 9. Most significantly, the resonance centered at about $\delta=-44$ ppm clearly displays crosspeaks linking this resonance to all of the other NMR signals, suggesting ${ }^{1} J$ spin-spin couplings and hence direct connectivity of the corresponding $\mathrm{P}$ atom to all of the other $\mathrm{P}$ sites. Therefore, we must assign this signal to the $\mathrm{Cu}$-bonded $\mathrm{P} 1\left(\mathrm{P}^{\prime}\right)$ sites, whereas the resonance close to $\delta=$ 94 ppm belongs to the copper coordinated P2(P2') sites, based on the REAPDOR result. The assignment of the remaining two resonances at 83.6 and $105.2 \mathrm{ppm}$ to $\mathrm{P} 3$ or $\mathrm{P} 4$ remains ambiguous, because the complete interpretation of the crosspeak structure linking the three downfield resonances is impeded by the limited chemical shift resolution available. However, the assignment may be finalized in principle, if it were possible to reduce the peak overlap at significantly higher magnetic field strengths.

\section{3. $(\mathrm{CuI})_{3} \mathrm{P}_{4} \mathrm{Se}_{4}$}

The crystal structure of this compound is based on monomeric $\beta-\mathrm{P}_{4} \mathrm{Se}_{4}$ cages having $C_{\mathrm{s}}$ symmetry, which are embedded between columns of copper iodide. Three of the four phosphorus atoms are coordinated by copper, whereas selenium is exclusively bonded to phosphorus. In Fig. 10, a projection of the crystal structure is shown, illustrating the stacking of the $\beta-\mathrm{P}_{4} \mathrm{Se}_{4}$ cages along the $c$-axis. The coordination spheres for the copper atoms can be depicted as $\left[\mathrm{CuPI}_{3}\right]$. $\mathrm{Cu} 1$ is centered within a distorted tetrahedron comprised of the phosphorus atom $\mathrm{P} 1$ and three iodine atoms. $\mathrm{Cu} 2$ and $\mathrm{Cu} 3$ are located within a tetrahedral environment of P4 and $3 \times \mathrm{I} 2$ $(\mathrm{Cu} 2)$, and $\mathrm{P} 3$ and $3 \times \mathrm{I} 3(\mathrm{Cu} 3)$, respectively.

The ${ }^{65} \mathrm{Cu}$ MAS spectrum of $(\mathrm{CuI})_{3} \mathrm{P}_{4} \mathrm{Se}_{4}$ is shown in Fig. 11, including the fit to three distinct lineshape components reflecting the influence of second-order quadrupolar effects. The corresponding quadrupolar coupling constants extracted using the DMFIT program are summarized in Table 2. Based on the fact that the local environments for $\mathrm{Cu} 2$ and $\mathrm{Cu} 3$ are very similar, we attribute the broad resonance centered near 250

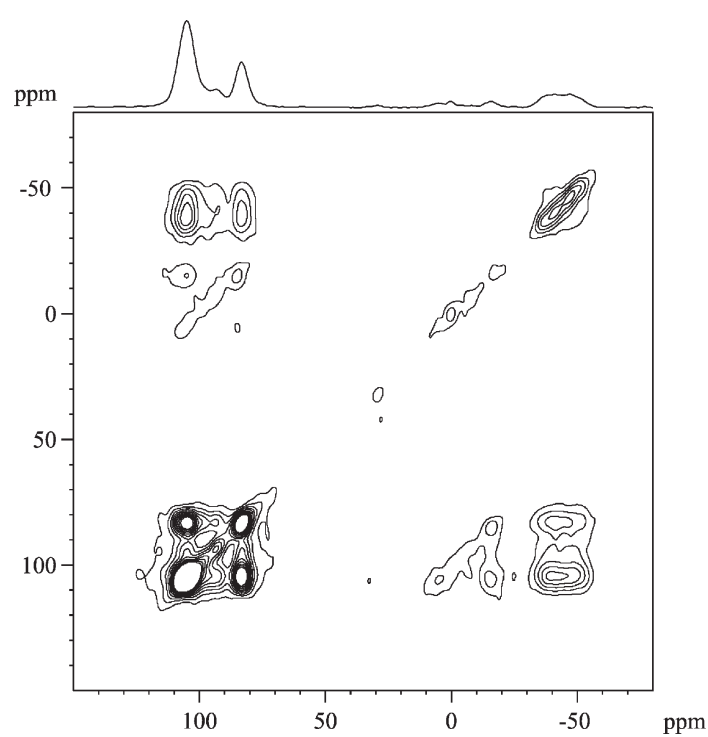

Fig. $9{ }^{31} \mathrm{P}-30 \mathrm{kHz}$ MAS R-TOBSY spectrum of $(\mathrm{CuI})_{2} \mathrm{P}_{8} \mathrm{Se}_{3}$ at 11.7 $\mathrm{T}(202.49 \mathrm{MHz})$ under the following experimental conditions: $\tau_{\text {mix }}=2.0 \mathrm{~ms}, 102 t_{1}$ increments at steps of $16.67 \mu \mathrm{s}$, relaxation delay $90 \mathrm{~s}$. Ten positive contour levels between $2 \%$ and $30 \%$ of the maximum peak intensity were plotted. The $F_{2}$ projection is shown on the top. 


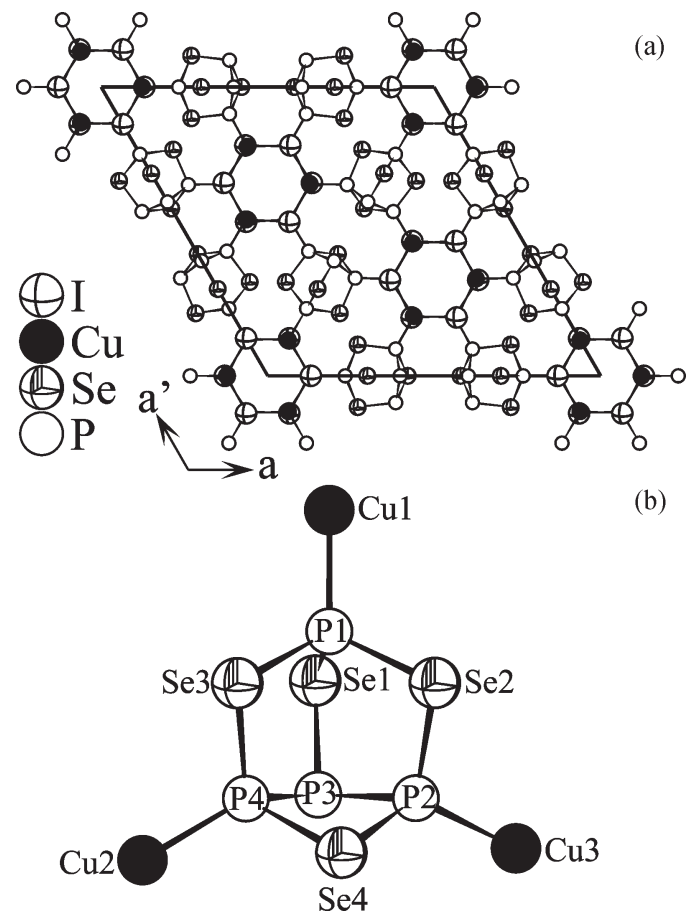

Fig. 10 (a) Projection of the crystal structure of $(\mathrm{CuI})_{3} \mathrm{P}_{4} \mathrm{Se}_{4}$ along [001]. The $\beta-\mathrm{P}_{4} \mathrm{Se}_{4}$ cages are stacked along the $c$-axis and surrounded by columns of $\mathrm{CuI}$ producing the motif of a hexagonal rod packing. (b) The labeling of the $\beta-\mathrm{P}_{4} \mathrm{Se}_{4}$ cage and its coordination to copper atoms.

ppm to these two $\mathrm{Cu}$ sites. This assignment is also consistent with the expectation that the least distorted site $\mathrm{Cu} 1$ gives rise to the NMR signal with the smallest quadrupolar coupling constant.

Fig. 12 shows the ${ }^{31} \mathrm{P}$ MAS-NMR spectrum, recorded at 303.59 $\mathrm{MHz}(17.6 \mathrm{~T})$, demonstrating significantly enhanced resolution over the previously reported spectrum at $11.7 \mathrm{~T} .^{13}$ At 17.6 T, the characteristic ${ }^{31} \mathrm{P}_{-}{ }^{63,65} \mathrm{Cu}$ scalar coupling multiplets associated with the $\mathrm{Cu}$-bonded phosphorus atoms $\mathrm{P} 1$ and $\mathrm{P} 2 / \mathrm{P} 4$ are adequately resolved whereas the resonances due to the chemically very similar P2 and P4 sites are strongly overlapping. Hence, taking into account the presence of both ${ }^{63} \mathrm{Cu}$ and ${ }^{65} \mathrm{Cu}$ isotopes, the full spectral deconvolution of the ${ }^{31} \mathrm{P}$ resonance multiplet structure requires six different multiplets. Table 2 summarizes the results obtained using the

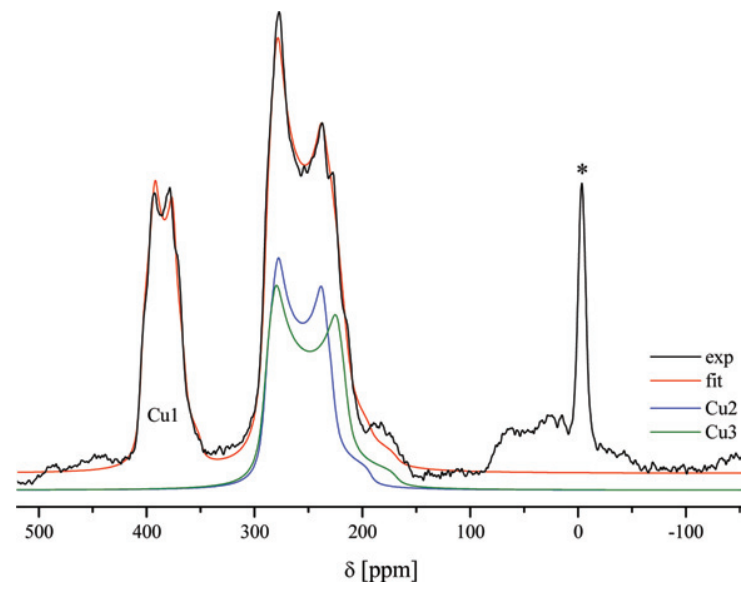

Fig. $11{ }^{65} \mathrm{Cu}$ MAS NMR spectrum of $(\mathrm{CuI})_{3} \mathrm{P}_{4} \mathrm{Se}_{4}$ at $11.7 \mathrm{~T}(142.00$ $\mathrm{MHz}$ ) and a spinning frequency of $30 \mathrm{kHz}$. The narrow peak marked with an asterisk indicates $\mathrm{CuI}$ impurity phase. The contributions of the two slightly distinct copper atoms $\mathrm{Cu} 2$ and $\mathrm{Cu} 3$ to the overall lineshape are also shown.

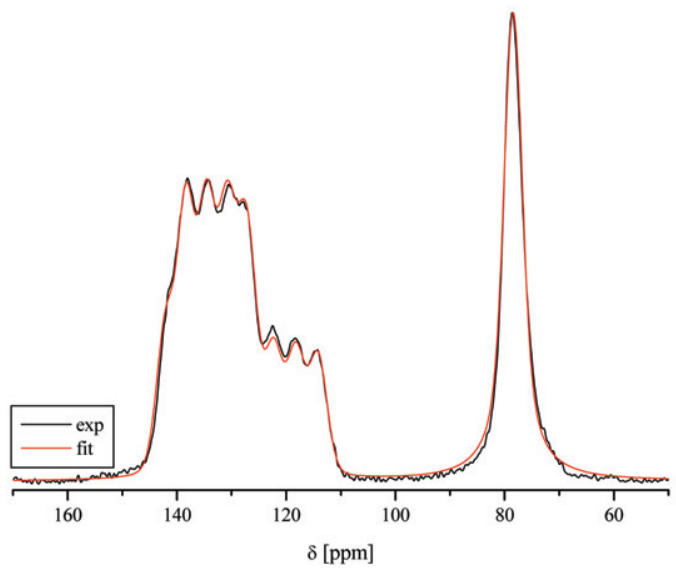

Fig. $12{ }^{31} \mathrm{P}$ MAS spectrum of $(\mathrm{CuI})_{3} \mathrm{P}_{4} \mathrm{Se}_{4}$ at $17.6 \mathrm{~T}(303.59 \mathrm{MHz})$ and a spinning frequency of $32.8 \mathrm{kHz}$. The spectrum was kindly provided by Prof. Eike Brunner (University of Regensburg).

WSOLIDS1 routine, which was applied in the same fashion as described above for $(\mathrm{CuI}) \mathrm{P}_{4} \mathrm{Se}_{4}$, revealing excellent agreement with the experimental spectrum. Both the ${ }^{31} \mathrm{P}$ and the ${ }^{65} \mathrm{Cu}$ MAS-NMR spectra nicely confirm the proposed crystal structure especially emphasizing the presence of the novel molecular $\beta-\mathrm{P}_{4} \mathrm{Se}_{4}$ cages.

\section{4. $(\mathrm{CuI})_{3} \mathrm{P}_{4} \mathrm{~S}_{4}$}

The structure of this material has similarities to the previously described selenium derivative and consists of monomeric $\beta$ $\mathrm{P}_{4} \mathrm{~S}_{4}$ cage molecules that are separated by hexagonal columns of CuI. Two distinct fully occupied copper sites instead of three in the case of $(\mathrm{CuI})_{3} \mathrm{P}_{4} \mathrm{Se}_{4}$ were found. Again, three of the four phosphorus atoms are bonded to copper whereas no bonds between copper and sulfur are observed. The molecular structure of the $\beta-\mathrm{P}_{4} \mathrm{~S}_{4}$ cage is found to be similar to those cages reported for the compound $\left[\beta-\mathrm{P}_{4} \mathrm{~S}_{4}\left(\mathrm{NbCl}_{5}\right)_{2}\right] .{ }^{9}$ A projection of the crystal structure of $(\mathrm{CuI})_{3} \mathrm{P}_{4} \mathrm{~S}_{4}$ along the $c$-axis as well as the labeling scheme for the $\beta-\mathrm{P}_{4} \mathrm{~S}_{4}$ cage is presented in Fig. 13. ${ }^{11}$

Since the elements phosphorus and sulfur are hard to distinguish by X-ray diffraction methods due to their very similar scattering powers, comparison with structural results from complementary experimental techniques is desirable. The ${ }^{63,65} \mathrm{Cu}$ MAS spectra ( $c f$. Fig. 14) show two well-resolved sites with an integrated area ratio of approximately $1: 2$, in agreement with the crystal structure. For both sites, the distortion from tetrahedral symmetry, as caused by $\mathrm{Cu}-\mathrm{P}$ bonding, generates both a substantial downfield chemical shift relative to the chosen $\mathrm{Cu}$-standard, solid $\mathrm{CuI}$, and significant local electric field gradients at the copper sites.

The ${ }^{31} \mathrm{P}$ MAS-NMR spectrum of $(\mathrm{CuI})_{3} \mathrm{P}_{4} \mathrm{~S}_{4}$, measured at $202.45 \mathrm{MHz}$ is shown in Fig. 15. Based on the integrated area ratio of 1:2:1 as well as the peak multiplicity structure, an unambiguous peak assignment is possible attributing the narrow line at $\delta=83.2 \mathrm{ppm}$ to the phosphorus site P3 while the copper-bonded sites $\mathrm{P} 1$ and $\mathrm{P} 2$ are identified due to their expected 1:2 area ratio. This assignment is confirmed further by a ${ }^{31} \mathrm{P}-\left\{{ }^{63} \mathrm{Cu}\right\}$-REAPDOR experiment, which was conducted using a recoupling pulse length of $33 \mu \mathrm{s}\left(\approx \tau_{\mathrm{r}} / 2\right)$ and a nutation frequency of $\omega_{1}=83.3 \mathrm{kHz}$ on the ${ }^{63} \mathrm{Cu}$ channel where the dipolar evolution time was set to $\approx 0.73 \mathrm{~ms}\left(11 \tau_{\mathrm{r}}\right)$. The resulting spectra (data not shown) reveal signal reductions of about $19 \pm 1 \%(\mathrm{P} 1-\mathrm{Cu} 1)$ and $16 \pm 1 \%(\mathrm{P} 2-\mathrm{Cu} 2)$, respectively. In contrast, the resonance associated with the phosphorus atom P3 nearly retains its original signal intensity $(\approx 2 \pm 1 \%$ loss $)$ in the REAPDOR experiments, because of its rather remote location from $\mathrm{Cu}$ atoms. A lineshape fit was 


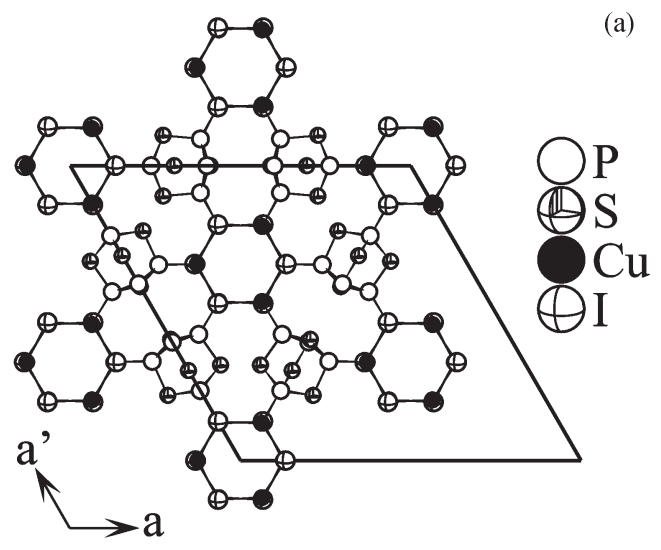

(b)

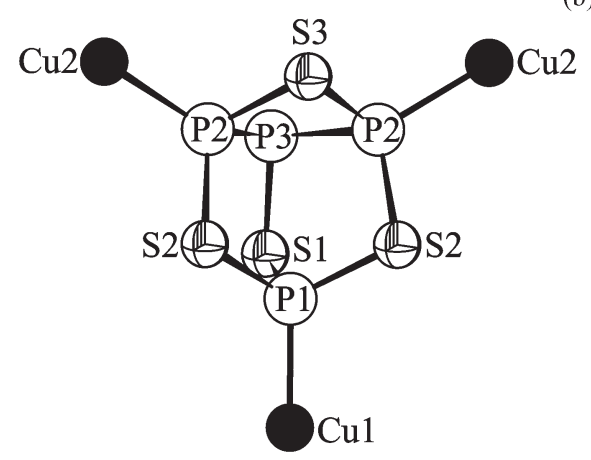

Fig. 13 (a) A projection of the crystal structure of $(\mathrm{CuI})_{3} \mathrm{P}_{4} \mathrm{~S}_{4}$ along the $c$-axis illustrating the sixfold rotation axis parallel to $c$. The two distinct copper atoms are ordered and attached to the phosphorus atoms $\mathrm{P} 1$ and $\mathrm{P} 2$. (b) The labelling scheme of the $\beta-\mathrm{P}_{4} \mathrm{~S}_{4}$ cage and its coordination to the copper atoms.

again obtained with the WSOLIDS1 routine, using the same procedure as described above for $(\mathrm{CuI}) \mathrm{P}_{4} \mathrm{Se}_{4}$. All the simulation results are collected in Table 2.

According to the crystal structure, the presence of the copper(I) halide matrix does not affect the connectivity of the $\beta$ $\mathrm{P}_{4} \mathrm{~S}_{4}$ cage itself. The latter can be studied in more detail using the R-TOBSY sequence. Figs. 16a and 16b show the 2D-correlation spectra recorded at two different mixing times. At short mixing times coherence transfer via ${ }^{1} J$ coupling interactions is significantly emphasized, allowing the selective detection of the P2-P3 correlation based on direct bond connectivity. With an increased mixing time, the weaker scalar interactions $\left({ }^{2} J\right)-\mathrm{P} 1-$ $\mathrm{S} 1-\mathrm{P} 3$ are also detected while the $\left({ }^{2} J\right)-\mathrm{P} 2-\mathrm{S} 2-\mathrm{P} 1$ crosspeaks have probably too small intensities because of the multiplet

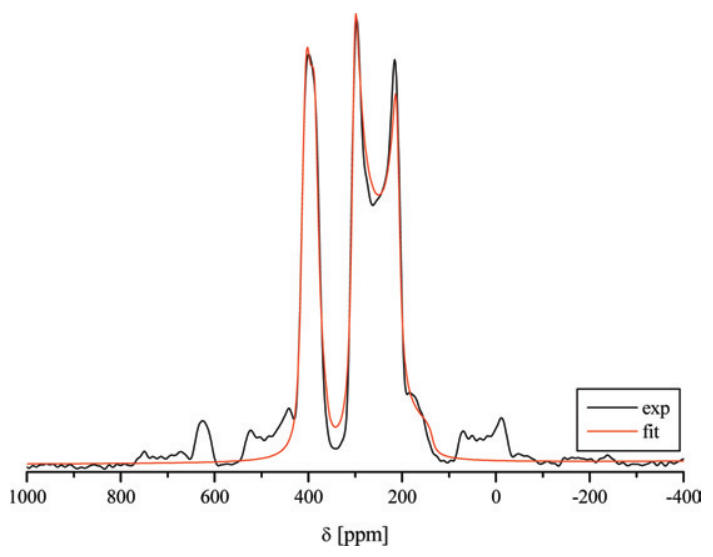

Fig. $14{ }^{63} \mathrm{Cu}$ MAS NMR spectrum of $(\mathrm{CuI})_{3} \mathrm{P}_{4} \mathrm{~S}_{4}$ at $11.7 \mathrm{~T}(132.50$ $\mathrm{MHz}$ ) and a spinning frequency of $30 \mathrm{kHz}$. The minor peaks are spinning side bands.

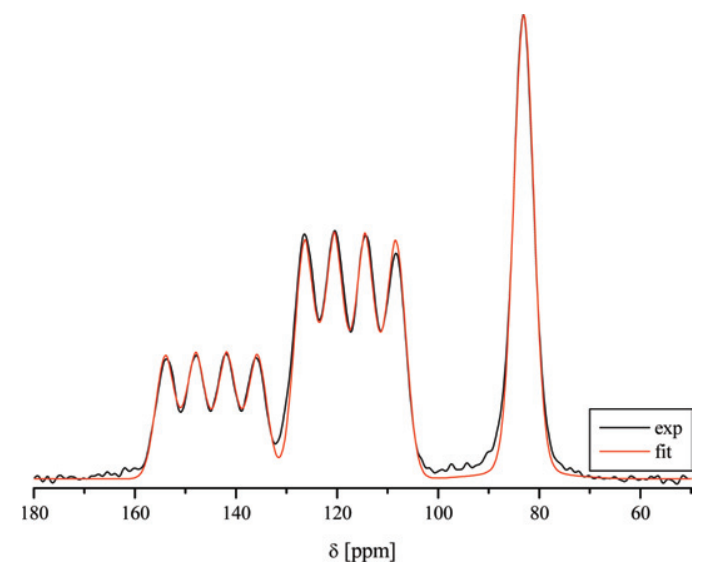

Fig. $15{ }^{31} \mathrm{P}$ MAS-NMR spectrum of $(\mathrm{CuI}){ }_{3} \mathrm{P}_{4} \mathrm{~S}_{4}$ at $11.7 \mathrm{~T}(202.45$ $\mathrm{MHz}$ ) and a spinning frequency of $30 \mathrm{kHz}$.

splittings involved. The square-shaped diagonal peaks associated with the copper-bonded $\mathrm{P} 1$ and $\mathrm{P} 2$ sites seem to suggest that 'autocorrelated' polarization transfer occurs. The nature of this process is indeed not too obvious. While for the site P2 a 'real' autocorrelation in the sense of scalar mediated polarization transfer would be possible $\left({ }^{2} J-\mathrm{P} 2-\mathrm{S} 3-\mathrm{P} 2^{\prime}\right)$, this is not feasible for the site P1. In the latter case the apparent 'autocorrelated' polarisation transfer is most likely an artifact caused by ${ }^{63,65} \mathrm{Cu}$ spin fluctuations due to spin-lattice interactions during the mixing time. As a result of such spin fluctuations, a fraction of those ${ }^{31} \mathrm{P}$ nuclei coupled to a given copper Zeeman state during the preparation period will be coupled to a different copper Zeeman state during the detection period, producing the apparent autocorrelation signal in the 2D-spectrum. Conceivably, this process also contributes to the squareshaped diagonal signal seen for the P2 site.

\section{Discussion and Conclusions}

While the above results have illustrated the inherent power of solid state NMR for the connectivity analysis of the phosphorus chalcogenide-copper iodide coordination compounds, this section focuses on the structural interpretation of the detailed ${ }^{31} \mathrm{P}$ and ${ }^{63,65} \mathrm{Cu}$ NMR Hamiltonian parameters, in relation to the interaction of the phosphorus chalcogenide molecules with the copper iodide matrix.

The ${ }^{31} P$ chemical shifts measured for the various phosphorus sites in the compounds studied here can be compared with published solution-state or solid-state NMR values obtained for the free cage molecules where possible. While $\beta-\mathrm{P}_{4} \mathrm{Se}_{4}$ and $\mathrm{P}_{8} \mathrm{Se}_{3}$ are hitherto unknown in the free, uncomplexed state, data are available for $\beta-\mathrm{P}_{4} \mathrm{~S}_{4},\left(\delta_{(\mathrm{P} 1)}=174.7 \mathrm{ppm}\right.$, $\delta_{(\mathrm{P} 2)}=207.5 \mathrm{ppm}$ and $\left.\delta_{(\mathrm{P} 3)}=85.7 \mathrm{ppm}^{37}\right)$ and for $\alpha-\mathrm{P}_{4} \mathrm{Se}_{4}$ $\left(\delta=127 \mathrm{ppm}^{38}\right)$. Inspection of Table 2 reveals that in each of these cases the coordination of a given $\mathrm{P}$ site with $\mathrm{Cu}(\mathrm{I})$ leads to pronounced upfield shift effects about $50 \mathrm{ppm}$ in magnitude, whereas the chemical shifts of the non-Cu-bonded sites are barely affected. Given the fact that ${ }^{31} \mathrm{P}$ chemical shifts of phosphorus sulfide and selenide cages are otherwise extremely sensitive to small changes in the local phosphorus bonding geometry, ${ }^{39}$ the results of the present study reveal that $\mathrm{Cu}^{+}$ complexation causes electronic perturbations that are predominantly local and mostly confined to the directly-bonded $\mathrm{P}$ atoms. Thus, in agreement with the diffraction data, the NMR results indicate that the overall cage geometry in these inclusion compounds changes very little in relation to the free molecules.

The isotropic ${ }^{31} \mathrm{P}_{-}{ }^{63,65} \mathrm{Cu}$ indirect spin-spin coupling constants measured in this work can be compared to values previously obtained for the large family of copper(I)-triphenylphosphine 

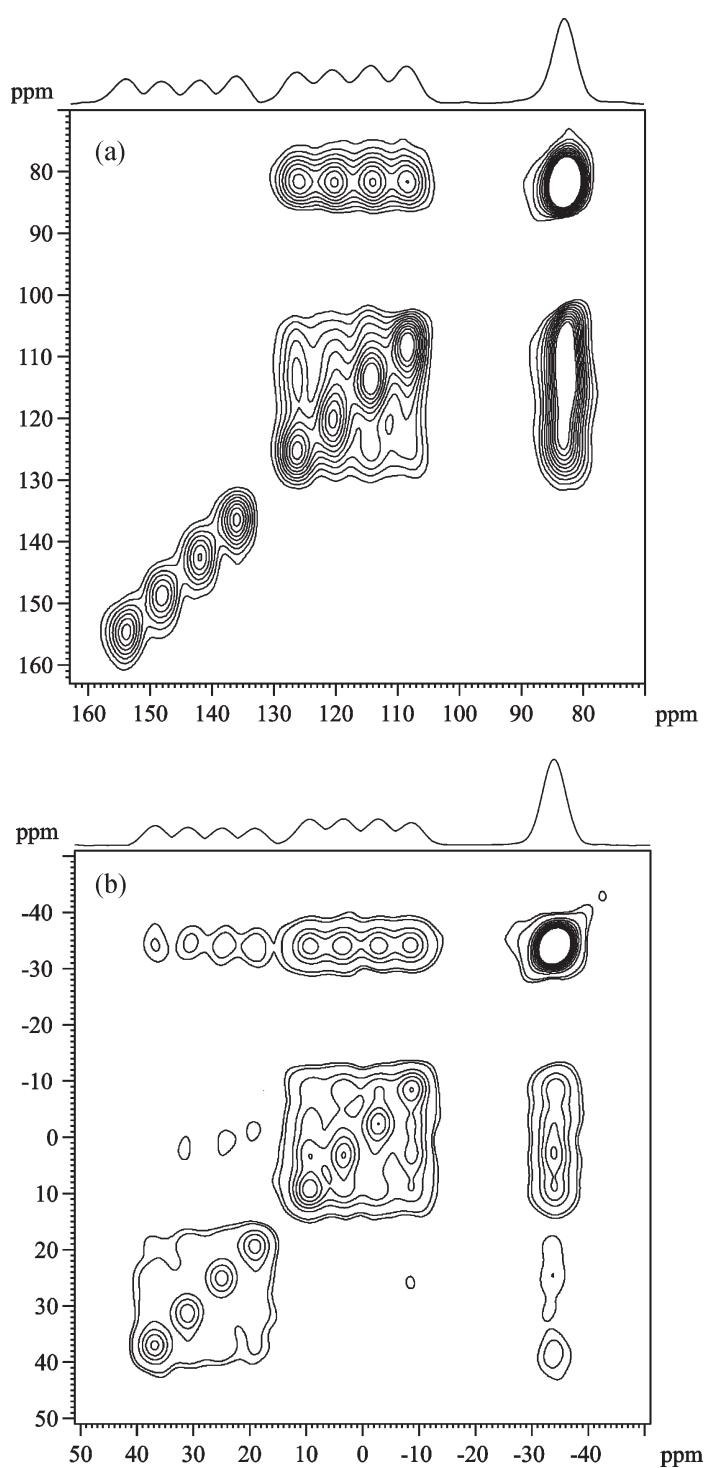

Fig. 16 (a) ${ }^{31} \mathrm{P}-25 \mathrm{kHz}$ MAS R-TOBSY spectrum of $(\mathrm{CuI})_{3} \mathrm{P}_{4} \mathrm{~S}_{4}$ at $11.7 \mathrm{~T}(202.47 \mathrm{MHz})$ under the following experimental conditions: $\tau_{\text {mix }}=4.8 \mathrm{~ms}, 62 t_{1}$ increments at steps of $40 \mu \mathrm{s}$, relaxation delay $420 \mathrm{~s}$. Quadrature detection in the $F_{1}$ dimension was achieved by the hypercomplex approach (STATES). Ten positive contour levels between $7 \%$ and $40 \%$ of the maximum peak intensity are plotted. The $F_{2}$ projection is shown on the top. (b) ${ }^{31} \mathrm{P}-30 \mathrm{kHz}$ MAS R-TOBSY spectrum of $(\mathrm{CuI})_{3} \mathrm{P}_{4} \mathrm{~S}_{4}$ at $11.7 \mathrm{~T}(202.47 \mathrm{MHz})$ under the following experimental conditions: $\tau_{\text {mix }}=19.2 \mathrm{~ms}, 70 t_{1}$ increments at steps of $33.33 \mu \mathrm{s}$, relaxation delay $210 \mathrm{~s}$. Quadrature detection in the $F_{1}$ dimension was achieved by the hypercomplex approach (STATES). Ten positive contour levels between $2 \%$ and $40 \%$ of the maximum peak intensity are plotted. The $F_{2}$ projection is shown on the top.

halide complexes representing the $\mathrm{Cu}$ local geometries $\left[\mathrm{CuP}_{4-n} \mathrm{Hal}_{n}\right]$, where $4>n>0$, and $\mathrm{Hal}=\mathrm{Cl}, \mathrm{Br}, \mathrm{I} \cdot{ }^{15,40-44}$ The coupling constants of these complexes are quite sensitive to the number $n$ and the type of halide atoms attached to $\mathrm{Cu}$, reflecting a good negative linear correlation $(R=0.987)$ between ${ }^{1} J\left({ }^{31} \mathrm{P}-{ }^{63} \mathrm{Cu}\right)$ and the copper-phosphorus distance $d_{(\mathrm{P}-\mathrm{Cu})}$ (see Fig. 17). The copper halide adducts examined in the present work can be divided into two groups, namely those with $\left[\mathrm{CuPI}_{3}\right]$ and those with $\left[\mathrm{CuP}_{2} \mathrm{I}_{2}\right]$ copper coordination spheres. While there still appears to be some correlation with $d_{(\mathrm{P}-\mathrm{Cu})}$, the experimental data of ${ }^{1} J\left({ }^{31} \mathrm{P}-{ }^{63,65} \mathrm{Cu}\right) v s . d_{(\mathrm{P}-\mathrm{Cu})}$ fall significantly below the correlation line established for the triphenylphosphine halide complexes. For example, the $\left[\mathrm{CuPI}_{3}\right]$-type compounds $(\mathrm{CuI})_{3} \mathrm{P}_{4} \mathrm{~S}_{4}\left(d_{(\mathrm{P}-\mathrm{Cu})}=222 / 224 \mathrm{pm}\right)$ and $(\mathrm{CuI})_{3} \mathrm{P}_{4} \mathrm{Se}_{4}\left(d_{(\mathrm{P}-\mathrm{Cu})}=224\right.$ to $\left.227 \mathrm{pm}\right)$ have coupling constants ranging from 1100 to $1210 \mathrm{~Hz}$ compared to values of

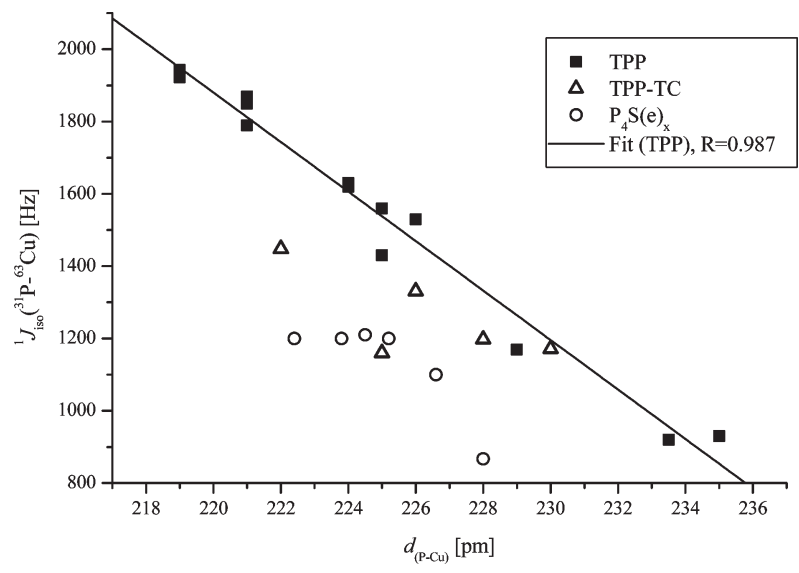

Fig. 17 Plot of ${ }^{1} J_{\text {iso }}\left({ }^{31} \mathrm{P}_{-}{ }^{63} \mathrm{Cu}\right)$ vs. Cu-P distance $d_{\mathrm{P}-\mathrm{Cu}}$ for copper halide triphenylphosphine complexes, (TPP) for copper thiocarboxylate triphenylphosphine complexes, (TPP-TC) and for the compounds of the present study $\left(\mathrm{P}_{4} \mathrm{~S}(\mathrm{e})_{x}\right)$.

1570-1700 $\mathrm{Hz}$ reported for the $\left[\mathrm{CuPI}_{3}\right]$-type complex $\left[\mathrm{PPh}_{3} \mathrm{CuI}\right]_{4}$ (cube) $\left(d_{(\mathrm{P}-\mathrm{Cu})}=223 \mathrm{pm}\right)$ even though the internuclear distances are comparable. Similar ligand influences were previously observed for a series of $\mathrm{Cu}(\mathrm{I})$ triphenylphosphine thiocarboxylate complexes, ${ }^{40}$ for which data have been included in Fig. 17 as well. Concerning the $\left[\mathrm{CuP}_{2} \mathrm{I}_{2}\right]$-type complex $(\mathrm{CuI}) \mathrm{P}_{4} \mathrm{Se}_{4}\left(d_{(\mathrm{P}-\mathrm{Cu})}=228 \mathrm{pm}\right)$ the coupling constant of $867 \mathrm{~Hz}$ also falls below the correlation line defined by the triphenylphosphine complexes. Additional $J$ values (not included in Fig. 17) for the $\left[\mathrm{CuP}_{2} \mathrm{Cl}_{2}\right]$ coordination-type compound $\left[\mathrm{CuCl}\left\{\mathrm{Cp} * \mathrm{Fe}\left(\eta^{5}: \eta^{1}: \eta^{1}-\mathrm{P}_{5}\right)\right\}\right]_{\infty}\left({ }^{1} J(\mathrm{P}-\mathrm{Cu}) \approx 466 \pm 10 \mathrm{~Hz}\right.$, $\left.d_{(\mathrm{P}-\mathrm{Cu})}=227 / 229 \mathrm{pm}\right)$ and for $\left[\mathrm{CuBr}\left\{\mathrm{Cp} * \mathrm{Fe}\left(\eta^{5}: \eta^{1}: \eta^{1}: \eta^{1}-\right.\right.\right.$ $\left.\left.\left.\mathrm{P}_{5}\right)\right\}\right]_{\infty}\left({ }^{1} J(\mathrm{P}-\mathrm{Cu}) \approx 560-780 \pm 10 \mathrm{~Hz}, d_{(\mathrm{P}-\mathrm{Cu})}=228 / 232 \mathrm{pm}\right)$ are even lower, reflecting the strong influence of the coordination ligand. ${ }^{45}$

A clear distinction of the various $\mathrm{Cu}$ coordination environments is given on the basis of the ${ }^{63,65} \mathrm{Cu}$ isotropic chemical shifts. Relative to the $\mathrm{CuI}$ standard (tetrahedral $\left[\mathrm{CuI}_{4}\right]$ coordination), the $\left[\mathrm{CuPI}_{3}\right]$ complexes resonate downfield near 300-400 ppm, while the $\left[\mathrm{CuP}_{2} \mathrm{I}_{2}\right]$ coordination environments are characterized by chemical shifts between 600 and 800 ppm downfield. For the five data points corresponding to the $\left[\mathrm{CuPI}_{3}\right]$ environment, Fig. 18a suggests a correlation $(R=$ $0.98)$ with the shear strain parameter

$$
\chi=\sum_{i=1}^{6} \tan \left|\alpha_{i}-109.48\right|
$$

which can serve as a measure of distortion from the tetrahedral bonding geometry. In this expression the $\alpha_{i}$ are the six individual ligand- $\mathrm{Cu}$-ligand angles, whose overall deviation from the ideal tetrahedral value is considered. Based on previous NMR studies of quadrupolar nuclei in distorted tetrahedral oxide geometries ${ }^{46}$ it also appears reasonable to expect a correlation of the shear strain parameter with the ${ }^{63,65} \mathrm{Cu}$ nuclear electric quadrupolar coupling constants. While the electric field gradient vanishes for the regular tetrahedral sites in cubic $\mathrm{CuI}$, the distortions produced by replacing one or two iodide ligands with $\mathrm{P}$ atoms result in $C_{\mathrm{Q}}$-values ranging from 3 to $10 \mathrm{MHz}$ in the present compounds. Within the range considered here, the $C_{\mathrm{Q}}$-values appear to be weakly correlated with $\chi$ (with a correlation coefficient of 0.90 ) suggesting that the extension of this semi-empirical approach to the more covalent compounds of the present study is more limited. Still, it is worth noting that the linear least squares fit passes close to the theoretically expected data point $\left\{C_{\mathrm{Q}}=0, \chi=0\right\}$, see Fig. 18b). The poor correlation between $C_{\mathrm{Q}}$ and $\chi$ is partly due to the fact that the length of the $\mathrm{Cu}-\mathrm{P}$ bond, which is also expected to influence the electric field gradient at the copper 

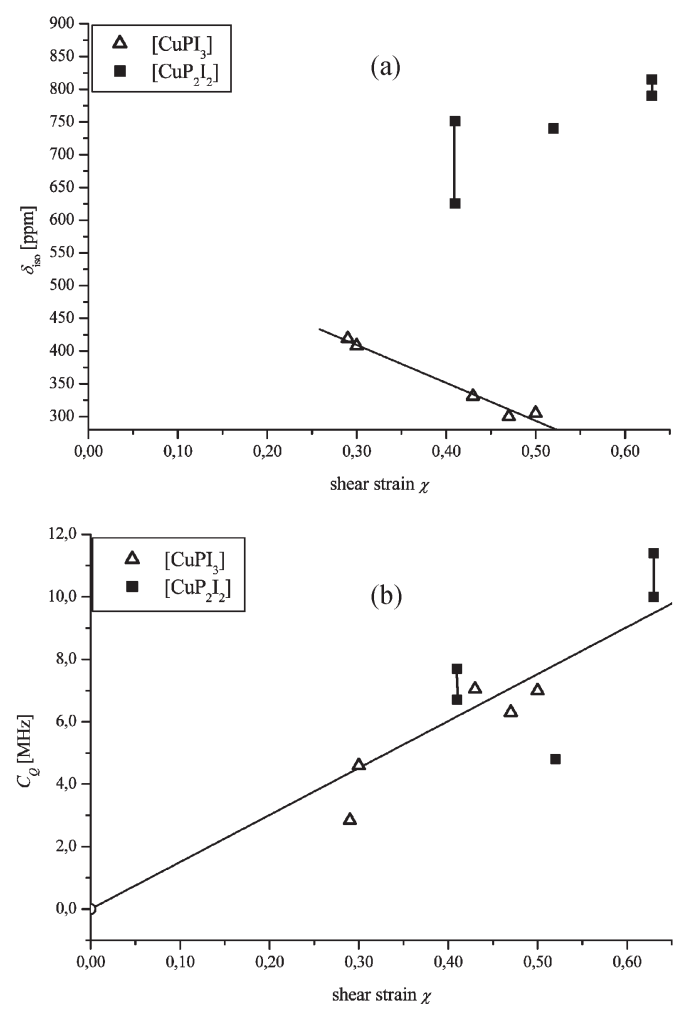

Fig. 18 (a) Plot of the experimental ${ }^{63,65} \mathrm{Cu}$ isotropic chemical shifts versus the empirical shear strain parameter $\chi$. Vertical lines indicate the parameter uncertainty between the static and MAS-NMR fits to the ${ }^{65} \mathrm{Cu}$ spectra of $(\mathrm{CuI})_{2} \mathrm{P}_{8} \mathrm{Se}_{3}$. (b) Plot of the experimental ${ }^{63} \mathrm{Cu}$ quadrupolar coupling constants $C_{\mathrm{Q}}$ versus the empirical shear strain parameter $\chi$. Vertical lines indicate the parameter uncertainty between the static and MAS-NMR fits to the ${ }^{65} \mathrm{Cu}$ spectra of $(\mathrm{CuI})_{2} \mathrm{P}_{8} \mathrm{Se}_{3}$.

sites, shows considerable variations (222 to $228 \mathrm{pm}$ ) for the $\mathrm{Cu}$ sites within the series of compounds examined here. Considering the fact that the copper-iodine atomic distances lie between 255 and $265 \mathrm{pm}$, a lengthening of the $\mathrm{P}-\mathrm{Cu}$ bonds is expected to produce a more symmetrical electron distribution around copper and hence reduce the $C_{\mathrm{Q}}$-values. In spite of the more complicated situation weakening the $C_{\mathrm{Q}} v s . \chi$ correlation here, our results suggest that it can still serve as a guide for ${ }^{63} \mathrm{Cu}$ signal assignments in each given compound when multiple $\mathrm{Cu}$ sites are present. Further quantitative insights should be sought not from semi-empirical considerations but rather from quantum-chemical field gradient calculations.

\section{Acknowledgements}

Generous funding of this work by the DFG and the Wissenschaftsministerium NRW is most gratefully acknowledged. G. B. thanks the Fonds der Chemischen Industrie for a doctoral stipend. We thank Professor Eike Brunner (University of Regensburg) for providing the ${ }^{31} \mathrm{P}$ MAS-NMR spectrum of $(\mathrm{CuI})_{3} \mathrm{P}_{4} \mathrm{Se}_{4}$, which was recorded at the $17.6 \mathrm{~T}$ spectrometer available at the University of Leipzig.

\section{References}

1 A. Pfitzner, Chem. Eur. J., 2000, 6, 1891.

2 A. Freudenthaler and A. Pfitzner, Solid State Ionics, 1997, 101103, 1053.

3 A. W. Cordes, R. D. Joyner, R. D. Shores and E. D. Dill, Inorg. Chem., 1974, 13, 132.
4 M. Di Vaira, M. Peruzzini and P. Stoppioni, J. Chem. Soc., Dalton Trans., 1985, 291.

5 M. Di Vaira, M. Peruzzini and P. Stoppioni, J. Chem. Soc., Chem. Commun., 1983, 903.

6 M. Di Vaira, M. Peruzzini and P. Stoppioni, J. Organomet. Chem., 1983, 258, 373.

7 M. Di Vaira, M. Peruzzini and P. Stoppioni, Inorg. Chem., 1983, 22, 2196.

8 A. Adolf, M. Gonsior and I. Krossing, J. Am. Chem. Soc., 2002, 124, 7111 .

9 H. Nowottnick, K. Stumpf, R. Blachnik and H. Reuter, Z. Anorg. Allg. Chem., 1999, 625, 693.

10 A. Pfitzner, S. Reiser and H. J. Deiseroth, Z. Anorg. Allg. Chem., 1999, 625, 2196.

11 S. Reiser, G. Brunklaus, J. H. Hong, J. C. C. Chan, H. Eckert and A. Pfitzner, Chem. Eur. J., 2002, 8, 4228.

12 A. Pfitzner, S. Reiser and T. Nilges, Angew. Chem. Int. Ed. Engl., 2000, 39, 4160

13 A. Pfitzner and S. Reiser, Inorg. Chem., 1999, 38, 2451.

14 E. M. Menger and W. S. Veeman, J. Magn. Reson., 1982, 46, 257.

15 A. C. Olivieri, J. Am. Chem. Soc., 1992, 114, 5758.

16 T. Gullion, J. Magn. Reson., 1995, A 117, 326.

17 A. E. Bennett, R. G. Griffin and S. Vega, NMR Basic Principles and Progress, 1994, 33, 1.

18 S. Dusold and A. Sebald, Annu. Rep. NMR Spectroscop., 2000, 41, 185.

19 M. Baldus and B. H. Meier, J. Magn. Reson. A, 1996, 121, 65.

20 M. Baldus, R. J. Iuliucci and B. H. Meier, J. Am. Chem. Soc., 1997, 119, 1121

21 S. Dusold, J. Kümmerlen and A. Sebald, J. Chem. Phys. A, 1997, 101, 5895 .

22 A. Lesage, C. Auger, S. Caldarelli and L. Emsley, J. Am. Chem. Soc., 1997, 119, 7867.

23 R. Verel, J. D. van Beek and B. H. Meier, J. Magn. Reson., 1999, 140, 300 .

24 A. Lesage, M. Bardet and L. Emsley, J. Am. Chem. Soc., 1999, 121, 10987.

25 X. Helluy, C. Marichal and A. Sebald, J. Phys. Chem. B, 2000, 104, 2836.

26 E. H. Hardy, R. Verel and B. H. Meier, J. Magn. Reson., 2001, 148, 459 .

27 A. S. D. Heindrichs, H. Geen, C. Giordani and J. J. Titman, Chem. Phys. Lett., 2001, 335, 89.

28 M. Carravetta, M. Edén, X. Zhao, A. Brinkmann and M. H. Levitt, Chem. Phys. Lett., 2000, 321, 205.

29 A. Brinkmann and M. H. Levitt, J. Chem. Phys., 2001, 115, 357.

30 J. C. C. Chan and G. Brunklaus, Chem. Phys. Lett., 2001, 349, 104 .

31 M. Bak, J. T. Rasmussen and N. C. Nielsen, J. Magn. Reson., 2000, 147, 296.

32 G. Brunklaus, PhD Dissertation, Münster, 2003.

33 D. Massiot, F. Fayon, M. Capron, I. King, S. Le Calvé, B. Alonso, J.-O. Durand, B. Bujoli, Z. Gan and G. Hoatson, Magn. Reson. Chem., 2002, 40, 70.

34 K. Eichele, R. Wasylishen, WSOLIDS1 V. 1. 17.34, Dalhousie University, 2001; K. Eichele, R. Wasylishen, Inorg. Chem., 1994, 33, 2766.

35 M. H. Levitt, in Supplement to the Encyclopedia of Nuclear Magnetic Resonance, eds., D. M. Grant and R. K. Harris, Wiley, 1996, in press.

36 D. J. States, R. A. Haberkorn and D. J. Ruben, J. Magn. Reson., 1982, 48, 286

37 A. M. Griffin, P. C. Minshall and G. M. Sheldrick, J. Chem. Soc., Chem. Commun., 1976, 809.

38 D. Lathrop and H. Eckert, J. Phys. Chem., 1989, 93, 7895.

39 H. Eckert, C. S. Liang and G. D. Stucky, J. Phys. Chem., 1989, 83, 452 .

40 F. Asaro, A. Camus, R. Gobetto, A. C. Olivieri and G. Pellizer, Solid State Nucl. Magn. Reson., 1997, 8, 81.

41 P. C. Healy, A. K. Whittaker, J. D. Kildea, B. W. Skelton and A. H. White, Austr. J. Chem., 1991, 44, 729.

42 G. A. Bowmaker, A. Camus, P. C. Healy, B. W. Skelton and A. H. White, Inorg. Chem., 1989, 28, 3883.

43 G. A. Bowmaker, B. W. Skelton, A. H. White and P. C. Healy, J. Chem. Soc. Dalton Trans., 1988, 2825.

44 S. Kroeker, J. V. Hanna, R. E. Wasylishen, E. W. Ainscough and A. M. Brodie, J. Magn. Reson., 1998, 135, 208.

45 G. Brunklaus, H. Eckert and M. Scheer, to be published.

46 M. T. Weller, M. E. Brenchley, D. C. Apperley and N. A. Davies, Solid State Nucl. Magn. Reson., 1994, 3, 103. 